\title{
Management of adrenal insufficiency during Ramadan fasting: a survey of physicians
}

\author{
Salem A Beshyah ${ }^{1,2}$, Khawla F Ali ${ }^{3}$ and Hussein F Saadi ${ }^{4}$ \\ ${ }^{1}$ Department of Medicine, Dubai Medical College, Dubai, United Arab Emirates \\ ${ }^{2}$ Diabetes and Endocrine Clinic, Mediclinic Airport Road Hospital, Abu Dhabi, United Arab Emirates \\ ${ }^{3}$ Department of Medicine, Royal College of Surgeons in Ireland Medical University of Bahrain, Adliya, Bahrain \\ ${ }^{4}$ Department of Endocrinology, Medical Subspecialties Institute, Cleveland Clinic Abu Dhabi, Abu Dhabi, United Arab Emirates \\ Correspondence should be addressed to K F Ali: kali@rcsi-mub.com
}

\begin{abstract}
Introduction: Appropriate dose adjustments of glucocorticoids replacement therapy for adrenal insufficiency (Al) is vital.

Objective: We sought to scope physicians' perceptions, and practices regarding Ramadan fasting (RF) impact on the management of Al.

Methods: A web-based survey of a convenience sample of endocrinologists.

Results: Nearly two-thirds of 145 respondents (64.1\%) were adult endocrinologists and almost half (49\%) saw more than 10 hypoadrenal patients per year. Most respondents (78.6\%) prescribed hydrocortisone, while the minority prescribed other preparations. The glucocorticoid doses were reportedly divided twice daily by $70.8 \%$ and thrice daily by $22.2 \%$ of respondents. Respondents recognized RF as having potential consequences in adrenal insufficiency patients included causing hypoglycaemia, undue tiredness, and fatigue, hypotension, feeling dizzy, and light-headedness. Symptoms of underreplacement were thought to happen in the late afternoon by $59.3 \%$ of respondents. Almost half (45.5\%) of respondents thought that RF has some probable or definite impact on glucocorticoid therapy that certainly warrants specific concern and possible action. Three quarters (76.4\%) of respondents confirmed providing specific management recommendations during RF. The most frequently reported recommendation was taking in the usual morning dose of hydrocortisone just before pre-dawn meal (Suhor) (57.8\%). A third switch patients from hydrocortisone to prednisolone/prednisone. Half reported providing patients with specific recommendations regarding breaking their fast and/or seeking help if hypoadrenal symptoms occur.

Conclusions: There is a remarkable variation in the physicians' perceptions and practices regarding the management of Al during Ramadan. This warrants professional effort to increase the awareness and dissemination of evidence-based guidelines.
\end{abstract}

\author{
Key Words \\ - management \\ - adrenal insufficiency \\ - Ramadan fasting \\ - survey \\ - physicians' perceptions
}

\section{Introduction}

Fasting the holy month of Ramadan, one of the five pillars of Islam, is a religious obligation practiced by Muslims for centuries. The religious practice mandates abstinence from food, water, and all oral substances from dawn to sunset. To achieve good holistic management, harmony is needed between physicians and religious scholars (1).
Fasting entails protracted periods of fasting, often exceeding 12-h per day. Prolonged abstinence, particularly in hot climates, subjects many to dehydration, fatigue, dizziness, hypoglycaemia, and hypotension $(2,3)$. Given such, several at-risk groups (i.e. the elders, the pregnant, and the sick) have been exempted from fasting. https://ec.bioscientifica.com

https://doi.org/10.1530/EC-20-0314

C 2020 The authors Published by Bioscientifica Ltd
Endocrine Connections (2020) 9, 804-811 
Despite the ease in restrictions, many with critical illnesses still chose to fast, subjecting themselves to unforeseen risks and challenges. Management of a number of chronic medical conditions in Ramadan has been addressed by Beshyah et al. (4). In endocrinology, the management of diabetes mellitus has attracted the most attention with the largest volume of literature (5). Nevertheless, significant deficiencies remain in guidance toward the management of other endocrinological disorders during Ramadan (6).

Adrenal insufficiency (AI) represents a major healthcare challenge for patients and physicians during the month of Ramadan. If inappropriately or inadequately managed, AI can lead to anorexia, fatigue, dizziness, nausea, vomiting, hypoglycaemia, hypotension, shock, and potentially death $(7,8)$. In the real world, significant barriers to diagnosis and management of adrenal insufficiency have been identified in developing regions of the world mostly on basis of resource limitation (9).

The dynamics of everyday life change significantly during Ramadan, impacting to a great extent the management of AI. Fasting involves abstinence from food, drinks and medications between dawn and sunset, constituting periods longer than the usual time frame between conventional doses. There is also a major change in the sleep/wake cycles when people may stay up till the late hours of the night, and occasionally wake up during the late hours of the afternoons or evenings. A degree of dehydration is also inevitable particularly in hot zones. Furthermore, from a professional view point, the challenge of AI management during Ramadan stems primarily from the lack of strong and uniform evidence on the topic. Without clear guidance from the field, many physicians are led astray while managing this vulnerable cohort. Also, without a clear scientific voice, religious guidance suffers; rendering patients who wish to fulfil their religious obligations vulnerable to complications $(10,11,12,13)$. A couple of review articles attempted to offer guidance on the management of AI during Ramadan. Mostly based on physiological principles and pharmacological knowledge and on extrapolation from other clinical situations $(6,14,15)$.

The first and most crucial step in addressing such deficiencies starts with an up-to-date assessment of physicians' practices and perceptions of AI management during the month of Ramadan. This current crosssectional assessment, aimed at assessing the latter, will highlight areas of deficiencies in the care of AI patients in Ramadan, thereby helping direct further education and research.

\section{Materials and methods}

\section{Study design}

This cross-sectional electronic questionnaire-based study was conducted between 10 February 2020 and 10 May 2020. For the creation, dissemination, and analysis of the questionnaire, Survey Monkey® (SVMK Inc., San Mateo, CA, USA) was used. The questionnaire was electronically sent to a convenience sample of healthcare professionals primarily residing and practicing in the Middle East and Africa and who are likely to be involved in the management of adrenal insufficiency. The practicing physicians and academics were identified on academic databases of health-related bodies, professional groups, and recent continuous professional development events (e.g. American Association of Clinical Endocrinologists Gulf Chapter annual meetings) and/or by virtue of their contribution to the medical literature. The initial invitation email explained the rationale of the study with link to the survey as was previously described $(9,16,17)$ Biweekly reminders were sent for non-responders and partial responders. Repeat submissions from the same internet protocol address were automatically blocked by the survey service.

\section{Survey questionnaire}

The questions were developed de novo based on a review of the literature. The survey included questions pertaining to diagnostic evaluation and choice of therapy. Most questions required a single best response to being selected from multiple choices. A broad range of choices was given, arranged alphabetically, numerically, or in random order. A few questions were included to define the demographic and professional profiles of respondents (Table 1 ).

\section{Data management and analysis}

Survey responses were anonymously collected and stored electronically by the survey service, accessible in a password-protected manner. Responses from those who met the inclusion criteria only were included (adult and pediatric endocrinologists, general internal medicine specialists with interest, and practice in endocrinology). A total of 186 respondents consented to participate, with 145 providing adequate responses for inclusion in the analysis and formed the basis of this study. No data were captured on non-consenting

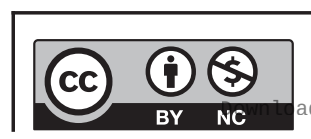

This work is licensed under a Creative Commons Attribution-NonCommercial 4.0 International License. ded from Bioscientifica.com at 04/26/2023 09:42:29AM 
Table 1 The survey questionnaire's domains, questions, and potential responses. $^{a}$

A. Demographic and professional profiles:

1. Age ( $<30$ years; $31-50$ years; $51-70$ years; $>70$ years).

2. Sex (male, female).

3. Specialty (adult endocrinologist, internal physician with endocrine interest, physician in general internal medicine, pediatric endocrinologist, general pediatrician; primary care; other).

4. Please indicate your current grade (Senior, Mid-grade, Junior).

5. Type of practice (Academic, Public health services, Private sector).

6. Region residence (Sub-Saharan Africa, North Africa, Arabian Gulf, Rest of the Middle East. Southeast Asia, Rest of the world) and specify the country ....

B. Ramadan-adrenal questionnaire:

1. How many patients with adrenal insufficiency do you treat in a year? $(0,1-10,11-25,26-50,>50)$.

2. What proportion of these patients are likely to observe the fasting of Ramadan 2020 (None, 25\%; 50\%; 75\%; All).

3. Which glucocorticoid preparation do you, most commonly, use for replacement therapy? (Hydrocortisone, Cortisone acetate, Prednisone/Prednisolone, Long-acting prednisolone, Dexamethasone).

4. How do you usually divide the daily dose of glucocorticoids used for replacement therapy? (Once daily (full dose), Twice daily, Three times daily, Four times daily).

5. How do you perceive the impact of Ramadan fasting (RF) on adrenal insufficiency and its management (There is no concern on glucocorticoid replacement therapy during Ramadan fasting whatsoever, Ramadan may have a possible impact on glucocorticoid replacement therapy during fasting but it does not warrant specific concern; Ramadan has some probable or definite impact on glucocorticoid replacement therapy during fasting that certainly warrants; specific concern and possible action, n6ot sure. 'It has never happened to me to consider this question before'.).

6. Features that may suggest an impact of Ramadan fasting on adrenal insufficiency and its management include: nausea and vomiting, undue tiredness and fatigue, hypoglycaemia, feeling dizzy and lightheaded, hypotension, Weight loss.

7. If any, at what time of the day symptoms of glucocorticoid under-replacement are likely to happen? (Early morning, Mid-Day, Late afternoon, Early evening, Late evening).

8. How I manage adrenal insufficiency and its management during Ramadan. (A. I DO provide specific recommendations. (Go to the next question); B. I DO NOT provide specific recommendations (end of the survey)).

9. Only if you have chosen A in the previous question, please tell us how do you adjust the dose of glucocorticoids used for replacement therapy during Ramadan (choose all that may apply): (I use hydrocortisone and delay the morning dose to latest possible time before Suhor and take the evening dose as usual with the first evening meal, Change all my patients on hydrocortisone and cortisone acetate to

prednisolone/prednisone, I warn my patients to break the fast and take their usual dose if they feel symptoms of under replacement, I warn my patients to break the fast and seek emergency help if they experience symptoms of the impending adrenal crisis.)

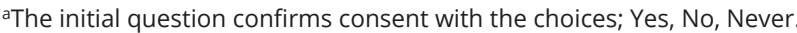
Logic is built in to allow only consenting respondents to proceed to take the survey. respondents nor those who did not provide reasonably complete answers. The survey management service tools were used for the examination of results and descriptive analysis. Summary statistics were prepared for responses to each question. Because not every participant answered all questions, the percentage of respondents providing a given answer was calculated individually for each question, using the number of respondents to that question as to the denominator.

\section{Results}

\section{Profiles of respondents}

The demographic and professional characteristics of the 145 respondents are detailed in Table 2 . The majority of respondents were from the Arabian Gulf (51.7\%), followed by the Middle East (15.2\%) and North Africa (14.5\%). There was a slight male preponderance (53.9\%). The majority $(55.9 \%, 39.3 \%)$ were in the age groups $31-50$ years and 51-70 years, respectively. Nearly two-thirds of respondents (64.1\%) were adult endocrinologists and almost onefifth $(18.6 \%)$ were pediatric endocrinologists (Table 2). Senior physicians (i.e. consultants/attending physicians) represented $81.2 \%$ of respondents. Almost equal numbers of respondents reported practicing in academic centres and public health services, while one-fifth was in the independent sector (Table 2). Just over half of respondents (51.0\%) reported seeing 1-10 hypoadrenal patients per year, while $22.1 \%$ see $11-25$ patients per year (Table 3 ). Most respondents (78.6\%) prescribed hydrocortisone, while the minority prescribed other preparations for replacement therapy (Table 3). The glucocorticoid doses were reportedly divided twice daily by $70.8 \%$ and thrice daily by $22.2 \%$ of respondents (Table 3 ).

\section{Impact of Ramadan on adrenal replacement therapy}

Of respondents, $29.4,13.3$, and $16.8 \%$ thought 25,50 , and $75 \%$ of their hypoadrenal patients are likely to observe the fasting of Ramadan, respectively (Table 3). Features recognized as potential consequences of Ramadan fasting in adrenal insufficiency patients included (in decreasing order): hypoglycaemia, undue tiredness, and fatigue, hypotension, feeling dizzy, and light-headedness (Table 3). Symptoms of glucocorticoid under-replacement were likely to happen in the late afternoon as reported by $59.3 \%$ of respondents.

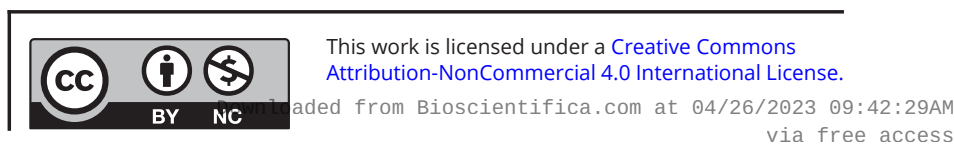


Table 2 The demographic and professional profiles. ${ }^{a}$

\begin{tabular}{|c|c|c|}
\hline Variables (respondent number) ${ }^{\mathbf{b}}$ & Details & Results $^{c}$ \\
\hline \multirow[t]{4}{*}{ Age (years) (145) } & $31-50$ & $81(56.3 \%)$ \\
\hline & $51-70$ & $57(39.1 \%)$ \\
\hline & $>70$ & $4(2.8 \%)$ \\
\hline & $<30$ & $3(2.1 \%)$ \\
\hline \multirow[t]{2}{*}{$\operatorname{Sex}(145)$} & Male & $78(53.9 \%)$ \\
\hline & Female & $67(46.2 \%)$ \\
\hline \multirow[t]{5}{*}{ Specialty (145) } & Adult endocrinologist & $93(64.1 \%)$ \\
\hline & Pediatric endocrinologist & $27(18.6 \%)$ \\
\hline & Internist with endocrine interest & $17(11.7 \%)$ \\
\hline & General internist & $6(4.14 \%)$ \\
\hline & General pediatrician & $2(1.4 \%)$ \\
\hline \multirow[t]{2}{*}{ Professional grade (145) } & Senior & $118(81.4 \%)$ \\
\hline & Mid-grade & $27(18.5 \%)$ \\
\hline \multirow[t]{3}{*}{ Type of medical practice (144) } & Academic/university & $57(39.6 \%)$ \\
\hline & Public health services & $55(38.2 \%)$ \\
\hline & Private sector & $32(22.2 \%)$ \\
\hline \multirow[t]{7}{*}{ Region of residence and practice (145) } & Arabian Gulf & $75(51.7 \%)$ \\
\hline & Rest of the Middle East & $22(15.2 \%)$ \\
\hline & North Africa & $21(14.5 \%)$ \\
\hline & South East Asia & $7(4.8 \%)$ \\
\hline & North America & $7(4.8 \%)$ \\
\hline & Sub-Saharan Africa & $6(4.1 \%)$ \\
\hline & Europe & $4(2.8 \%)$ \\
\hline
\end{tabular}

${ }^{\text {aD }}$ ata on maximal of 145 eligible respondents out of a total of 186 responses received. ${ }^{b}$ Numbers of responses to individual questions are indicated in parenthesis. 'Results are shown as number (\%).

\section{Adrenal replacement therapy during Ramadan}

Respondents' perceptions of the impact of Ramadan fasting on $\mathrm{AI}$ and their practices in management are detailed in Table 4 . Almost half (45.5\%) of respondents thought that Ramadan has some probable or definite impact on glucocorticoid replacement therapy during fasting that certainly warrants specific concern and possible action. About $37.1 \%$ reported Ramadan may have a possible impact on glucocorticoid replacement therapy during fasting but does not warrant specific concern. Three quarters (76.4\%) of respondents confirmed they provide specific recommendations regarding adrenal insufficiency management during Ramadan fasting (Table 4). The most frequently reported recommendation was taking the usual morning dose of hydrocortisone at the latest possible time with the pre-dawn meal or Suhor $(57.8 \%)$. Over a quarter (28.5\%) recommend switching patients from hydrocortisone to prednisolone or prednisone. Other management strategies, dose adjustments, and/or warnings reportedly adopted by physicians are detailed in Table 4. Only half reported providing patients with specific recommendations regarding breaking their fast and/or seeking help when hypoadrenal symptoms occur.

\section{Discussion}

AI is a relatively rare endocrine disorder, resulting from functional and/or structural defects at the level of the adrenals (primary AI or Addison's disease), pituitary (secondary AI), or hypothalamus (tertiary AI). While primary AI is primarily treated with glucocorticoid and mineralocorticoid replacement therapies, secondary and tertiary AI are managed with glucocorticoid replacement alone (8).

Oral hydrocortisone has been the preferred glucocorticoid replacement therapy in AI (7). Its relatively short half-life allows for frequent daily dosing, roughly mimicking the normal diurnal rhythm of cortisol $(8,11)$. According to the latest 2016 Endocrine Society guidelines, oral hydrocortisone is recommended to be administered in twice or thrice daily regimens, with the largest dose administered upon awakening, followed by a second dose in the early afternoon, and an optional smaller dose in the late afternoon (for three-dose regimen) (8).

A major challenge present in the management of AI during Ramadan has been the timing of hydrocortisone administration. With an estimated half-life of $1.5 \mathrm{~h}$, the concentrations of oral hydrocortisone are significantly diminished 4-6 $\mathrm{h}$ after its administration (12). 
Table 3 Respondents perceptions of the Impact of Ramadan fasting on adrenal insufficiency and its management. ${ }^{a}$

Questions ${ }^{\mathbf{b}}$
1. How many patients with adrenal insufficiency do you treat in a year?
2. What proportion of patients are likely to observe the Ramadan fastin
(in 2020)? (143)
3. Which glucocorticoid preparation do you, most commonly, use for
replacement therapy? (145)

4. How do you usually divide the daily dose of glucocorticoids for replacement therapy? (144)

5. Features that may suggest an impact of Ramadan fasting on adrenal insufficiency and its management include: (142)

6. Time of the day when symptoms of glucocorticoid under-replacement are likely to happen: (140)

\begin{tabular}{l}
\hline Response options \\
\hline $1-10$ \\
$11-25$ \\
$26-50$ \\
More than 50 \\
None \\
$25 \%$ \\
None \\
All of them \\
$75 \%$ \\
$50 \%$ \\
Hydrocortisone \\
Prednisone/prednisolone \\
Cortisone acetate \\
Long-acting prednisolone \\
Dexamethasone \\
Twice daily \\
Three times daily \\
Once-daily (full dose) \\
Four times daily \\
Hypoglycemia \\
Undue tiredness and fatigue \\
Hypotension \\
Feeling dizzy and lightheaded \\
Nausea and vomiting \\
Weight loss \\
Late afternoon \\
Mid day \\
Early evening \\
Early morning \\
Late evening \\
\hline
\end{tabular}

aData on maximal of 145 eligible respondents out of a total of 186 responses received. b Numbers of responses to individual questions are indicated in parenthesis. 'Results are shown as number (\%).

Oral hydrocortisone taken at pre-dawn would leave AI patients with sub-normal cortisol levels for numerous hours from early afternoon to sunset, thereby increasing their risk for adrenal crisis.

In our analysis of 145 respondents, the majority were senior physicians from tertiary hospitals. To the best of our knowledge, most patients with AI are primarily cared for by endocrinologists and physicians with special interest in endocrinology. Many respondents (45.5\%) correctly reported Ramadan fasting has an impact on the management of AI which warrants concerns and possible actions. However, the remainder of the respondent pool either reported possible impact but would not warrant concerns, no impact at all, or were not sure. The latter findings raise concerns regarding current knowledge of AI management in Ramadan, and thereby warrant a critical need for establishing uniform guidelines on the subject.

Current recommendations on adrenal replacement therapy in Ramadan are sparse and widely different. Some experts recommend taking higher doses of hydrocortisone at pre-dawn (3). Others recommend patients be switched to longer-acting formulations of glucocorticoids, such as prednisone/prednisolone, shortly before and during Ramadan, and to be taken at pre-dawn $(6,14,15)$. A few have suggested the addition of a small dose of hydrocortisone at sunset, complementing the earlier prednisone/prednisolone dose (6). In our analysis, more than half of our respondents recommended hydrocortisone to be used in Ramadan, but with an increase and delay in morning dose to the latest possible time before Suhor. A third recommend switching patients to a longer-acting formulation such as prednisolone/ prednisone. Although the switch to a longer-acting formulation is physiologically sound, a recent randomized double-blinded crossover clinical trial of subjects with AI showed no difference in rates of complications, mean blood glucose levels or health-related quality of life (HRQoL) between those receiving hydrocortisone or prednisolone replacement therapy during the month of Ramadan (18).

The introduction of newer formulations of modifiedand dual-release hydrocortisone (Chronocort ${ }^{\circledR}$ and https://ec.bioscientifica.com

https://doi.org/10.1530/EC-20-0314 (c) 2020 The authors Published by Bioscientifica Ltd
This work is licensed under a Creative Commons Attribution-NonCommercial 4.0 International License. ded from Bioscientifica.com at 04/26/2023 09:42:29AM via free access 
Table 4 Reported physicians' attitudes and practices regarding the management of adrenal insufficiency during Ramadan fasting.

Theme/question and response options ${ }^{\text {a }}$
I. How do you perceive the impact of Ramadan fasting (RF) on adrenal insufficiency and its management? ( $n=143$ )
A. Ramadan has some probable or definite impact on glucocorticoid replacement therapy during fasting that
certainly warrants specific concern and possible action.
B. Ramadan may have a possible impact on glucocorticoid replacement therapy during fasting but it does
not warrant specific concern.
C. Not sure. It has never happened to me to consider this question before.
D. There is no concern on glucocorticoid replacement therapy during Ramadan fasting whatsoever.
II. How do you approach the management of adrenal insufficiency during Ramadan? ( $n=140)$
A. I do provide specific recommendations:
B. I do not provide specific recommendations:
III. How do you adjust the dose of glucocorticoids used for replacement therapy during Ramadan? $(n=116)$.
(More than one option is possible.)
A. I use hydrocortisone and delay the morning dose to the latest possible time before Suhor and take the
evening dose with the evening meal.
B. Change all my patients who are on hydrocortisone and cortisone acetate to prednisolone/prednisone.
C. I warn my patients to break the fast and take their usual dose if they feel symptoms of under
replacement.
D. I warn my patients to break the fast and seek emergency help if they experience symptoms of an
impending adrenal crisis.

\begin{tabular}{c}
\hline Results $^{\mathbf{b}}$ \\
\hline $65(45.5 \%)$ \\
$53(37.1 \%)$ \\
$17(11.9 \%)$ \\
$8(5.6 \%)$ \\
$107(76.4 \%)$ \\
$33(23.6 \%)$ \\
$67(57.8 \%)$ \\
$33(28.5 \%)$ \\
$57(49.1 \%)$ \\
$61(52.6 \%)$ \\
\hline
\end{tabular}

${ }^{a}$ Number of responses are shown per question. ${ }^{b}$ Results are presented as number (\%).

Plenadren $\left.{ }^{\circledR}\right)$ may allow for safer fasting practices (19, 20). Chronocort ${ }^{\circledR}$, a modified-release formulation of hydrocortisone, administered twice daily at predawn and at sunset, has been shown to resemble the physiologic cortisol rhythm (20). Plenadren ${ }^{\circledR}$, a once-daily dualrelease formulation, with an extended-release core coated by an immediate-release formulation, can be administered once daily at predawn and may aid with patient compliance (21). Additionally, the use of continuous s.c. hydrocortisone infusions (CSHI) has safely brought ACTH and cortisol toward normal circadian levels without adversely affecting glucocorticoid metabolism in the way that $\mathrm{OHC}$ did. Positive effects on HRQoL were noted with CSHI, indicating that physiological glucocorticoid replacement therapy may be beneficial and that CSHI might become a treatment option for patients poorly controlled on conventional therapy (22). However, their cumbersome and expensive nature renders them unfavorable, particularly in Muslim-majority populations. Furthermore, a recent study compared metabolic effects of Modified-Release Hydrocortisone MR-HC with Standard Glucocorticoid (SG) replacement in adults with AI. Randomised control trials (RCTs) were meta-analysed; non-RCT studies described narratively with critical appraisal. Nine studies were included for review (RCT, $n=2$; non-RCT, $n=7$ ). The authors suggested that in adults with AI, replacement with MR-HC associates with significant improvements in anthropometric measurements and HbA1c compared with SG replacement, particularly those with DM (23).
It is important to acknowledge that the duration of fast varies across the globe and by season. Admittedly, the questionnaires did not address this. It is noteworthy that fasting hours differ considerably, with some countries fasting for as long as $21 \mathrm{~h}$, while some fast $<11 \mathrm{~h}$ a day. These variations may reflect prescribing habits analogous to those established in the management of diabetes during Ramadan. (24). The health implications of a very long periods of fasting for AI patients includes increased risk of dehydration and hypotension due to under replacement during the fasting period. Whereas, in areas and at times of short fasting durstion, no changes management may be required.

The management of AI during Ramadan should not only be limited to adjustment and/or titration of medications. Patient education is also a vital aspect of the prevention of complications associated with fasting. AI patients should be instructed to hydrate well during non-fasting periods, maintain normal salt intake, and avoid strenuous activities during fasting. The pre-dawn meal, or Suhor, should be rich in complex carbohydrates, healthy proteins, and fats, and should be delayed to right before fasting starts (25). Additionally, all patients should be instructed to carry a steroid emergency card and a medical alert bracelet at all times. They should be reminded of the sick day rules (double or triple the dose of glucocorticoids in the event of fever or illness requiring bed rest). AI patients should always be supplied with i.m. glucocorticoid preparations for self-injection in the event of severe illness, trauma, or persistent vomiting, and

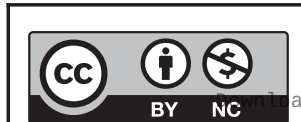

This work is licensed under a Creative Commons Attribution-NonCommercial 4.0 International License. ded from Bioscientifica.com at 04/26/2023 09:42:29AM 
advised to go to the hospital after the emergency injection (25). In our study, only half reported providing patients with specific recommendations regarding breaking their fast and/or seeking help when hypoadrenal symptoms occur, the latter of which may subject AI patients to unforeseen risks and preventable dangers.

\section{Conclusions}

Hitherto, the management of AI during the fasting month of Ramadan was mostly based on translating physiological principles and pharmacological knowledge with extrapolation of experiences from other clinical situations. We provided the first assessment of physicians' practices and perceptions of AI management during the month of Ramadan. We found a remarkable degree of variation in the physicians' perceptions and practices. This warrants professional effort to increase awareness, develop evidencebased guidelines, and disseminate them widely. There are several good recommendations that can be followed up. All AI patients need to (1) be assessed in the index endocrine consultation on their intentions to observe the fast and (if any) past glucocorticoid replacement experience during the previous Ramadan. (2) adjust the doses and formulations to cover their fasting periods and (3) educated to observe the 'sick day rules' and seek with specific instructions relating to interruption of fasting and seeking of emergency care.

\section{Disclaimer}

The views expressed in this manuscript are those of the respondents and authors and do not reflect any official policy of their employers or affiliates.

\section{Declaration of interest}

The authors declare that there is no conflict of interest that could be perceived as prejudicing the impartiality of the research reported.

\section{Funding}

This work did not receive any specific grant from any funding agency in the public, commercial, or not-for-profit sector.

\section{Compliance with ethical principles}

The study was approved by the Institutional Review Board at Sheikh Khalifa Medical City, Abu Dhabi, UAE. All participants provided informed written consent before he can proceed to the survey questions. Data were downloaded and analysed anonymously.

\section{Author contribution statement}

$S$ A B adopted the online version of the survey, managed the electronic survey and data extraction. S A B and K F A drafted the manuscript.
All authors revised the manuscript critically for intellectual content and approved its final version.

\section{Acknowledgement}

The authors would like to thank all the colleagues who participated in this survey.

\section{References}

1 Beshyah S. Fasting during the month of Ramadan for people with diabetes: medicine and fiqh united at last. Ibnosina Journal of Medicine and Biomedical Sciences 20091 58. (https://doi.org/10.4103/1947489X.211054)

2 Azizi F \& Rasouli HA. Serum glucose, bilirubin, calcium, phosphorus, protein and albumin concentrations during Ramadan. Medical Journal of the Islamic Republic of Iran $1987138-41$.

3 Samad F, Qazi F, Pervaiz MB, Kella DK, Mansoor M, Osmani BZ, Mir F \& Kadir MM. Effects of Ramadan fasting on blood pressure in normotensive males. Journal of Ayub Medical College, Abbottabad 2015 27 338-342.

4 Beshyah SA, Fathalla W, Saleh A, Al-Kaddour A, Noshi M, Al Hatheethi H, Al-Saadawi N, Elsiesi H, Amir N, Almarzouqi M, et al. Mini-symposium: Ramadan fasting and the medical patient: an overview for clinicians. Ibnosina Journal of Medicine and Biomedical Sciences 20102 240-257. (https://doi.org/10.4103/1947489X.211004)

5 Beshyah WS \& Beshyah SA. Bibliometric analysis of the literature on Ramadan fasting and diabetes in the past three decades (1989-2018). Diabetes Research and Clinical Practice 2019151 313-322. (https://doi. org/10.1016/j.diabres.2019.03.023)

6 Beshyah SA, Fiad TM \& Saadi HF. Management of common endocrine conditions other than diabetes mellitus during Ramadan fasting. Ibnosina Journal of Medicine and Biomedical Sciences 20124 137-146. (https://doi.org/10.4103/1947-489X.210770)

7 Debono M. Fasting during the Ramadan: a challenge for patients with adrenal insufficiency. Endocrine 201757 196-198. (https://doi. org/10.1007/s12020-017-1329-y)

8 Bornstein SR, Allolio B, Arlt W, Barthel A, Don-Wauchope A, Hammer GD, Husebye ES, Merke DP, Murad MH, Stratakis CA, et al. Diagnosis and treatment of primary adrenal insufficiency: an Endocrine Society clinical practice guideline. Journal of Clinical Endocrinology and Metabolism 2016101 364-389. (https://doi. org/10.1210/jc.2015-1710)

9 Mofokeng TRP, Beshyah SA, Mahomed F, Ndlovu KCZ \& Ross IL. Significant barriers to diagnosis and management of adrenal insufficiency in Africa. Endocrine Connections 20209 445-456. (https://doi.org/10.1530/EC-20-0129)

10 Chihaoui M, Grira W, Bettaieb J, Yazidi M, Chaker F, Rejeb O, Oueslati I, Feki M, Kaabachi N \& Slimane H. The risk for hypoglycaemia during Ramadan fasting in patients with adrenal insufficiency. Nutrition 201845 99-103. (https://doi.org/10.1016/j. nut.2017.07.014)

11 Bancos I, Hahner S, Tomlinson J \& Arlt W. Diagnosis and management of adrenal insufficiency. Lancet: Diabetes and Endocrinology 20153 216-226. (https://doi.org/10.1016/S22138587(14)70142-1)

12 Derendorf H, Möllmann H, Barth J, Möllmann C, Tunn S \& Krieg M. Pharmacokinetics and oral bioavailability of hydrocortisone. Journal of Clinical Pharmacology 199131 473-476. (https://doi. org/10.1002/j.1552-4604.1991.tb01906.x)

13 Ilias I, Tayeh LS \& Pachoundakis I. Diversity in endocrinology practice: the case of Ramadan. Hormones 201615 147-148. (https:// doi.org/10.14310/horm.2002.1630) 
14 Siddiqi SS, Singh SK, Khan SA, Ishtiaq O, Pathan MF, Raza SA, Khan AK, Zargar AH \& Bantwal G. Guidelines regarding management of adrenal insufficiency in the holy month of Ramadan. Indian Journal of Endocrinology and Metabolism 201216 519-521. (https:// doi.org/10.4103/2230-8210.97999)

15 Hussain S, Hussain S, Mohammed R, Meeran K \& Ghouri N. Fasting with adrenal insufficiency: practical guidance for healthcare professionals managing patients on steroids during Ramadan. Clinical Endocrinology 202093 87-96. (https://doi.org/10.1111/ cen.14250)

16 Beshyah SA, Sherif IH, Chentli F, Hamrahian A, Khalil AB, Raef H, El-Fikki M \& Jambart S. Management of prolactinomas: a survey of physicians from the Middle East and North Africa. Pituitary 201720 231-240. (https://doi.org/10.1007/s11102-016-0767-5)

17 Beshyah SA, Khalil AB, Sherif IH, Benbarka MM, Syed Abbas Raza SA, Hussein W, Alzahrani AS \& Chadli A. Clinical practice patterns in management of Graves' disease in the Middle East and North Africa. Endocrine Practice 201723 299-308. (https://doi.org/10.4158/ EP161607.OR)

18 Chihaoui M, Mimita W, Oueslati I, Rejeb O, Ben Amor Z, Grira W, Yazidi M \& Chaker F. Prednisolone or hydrocortisone replacement in patients with corticotrope deficiency fasting during Ramadan result in similar risks of complications and quality of life: a randomized double-blind controlled trial. Endocrine 202067 155-160. (https:// doi.org/10.1007/s12020-019-02082-w)

19 Johannsson G, Nilsson AG, Bergthorsdottir R, Burman P, Dahlqvist P, Ekman B, Engström BE, Olsson T, Ragnarsson O, Ryberg M, et al. Improved cortisol exposure-time profile and outcome in patients with adrenal insufficiency: a prospective randomized trial of a novel hydrocortisone dual-release formulation. Journal of Clinical
Endocrinology and Metabolism 201297 473-481. (https://doi. org/10.1210/jc.2011-1926)

20 Whitaker M, Debono M, Huatan H, Merke D, Arlt W \& Ross RJ. An oral multiparticulate, modified-release, hydrocortisone replacement therapy that provides physiological cortisol exposure. Clinical Endocrinology 201480 554-561. (https://doi.org/10.1111/cen.12316)

21 Stewart PM. Modified-release hydrocortisone: is it time to change clinical practice? Journal of the Endocrine Society 20193 1150-1153. (https://doi.org/10.1210/js.2019-00046)

22 Oksnes M, Björnsdottir S, Isaksson M, Methlie P, Carlsen S, Nilsen RM, Broman JE, Triebner K, Kämpe O, Hulting AL, et al. Continuous subcutaneous hydrocortisone infusion versus oral hydrocortisone replacement for treatment of Addison's disease: a randomized clinical trial. Journal of Clinical Endocrinology and Metabolism 201499 1665-1674. (https://doi.org/10.1210/jc.2013-4253)

23 Bannon C, Gallacher D, Hanson P, Randeva HS, Weickert MO \& Barber TM. Systematic review and meta-analysis of the metabolic effects of modified-release hydrocortisone versus standard glucocorticoid replacement therapy in adults with adrenal insufficiency. Clinical Endocrinology 2020 [epub]. (https://doi org/10.1111/cen.14275)

24 Afandi BO, Beshyah SA, Hassanein MM, Jabbar A \& Khalil AB. The individualization of care for people with diabetes during Ramadan fasting: a narrative review. Ibnosina Journal of Medicine and Biomedical Sciences 202012 98-107. (https://doi.org/10.4103/ijmbs. ijmbs_49_20)

25 Chihaoui M, Chaker F, Yazidi M, Wafa Grira W, Ben Amor Z, Rejeb O \& Slimane H. Ramadan fasting in patients with adrenal insufficiency. Endocrine 201755 289-292. (https://doi.org/10.1007/s12020-0161186-0)

Received in final form 27 July 2020

Accepted 30 July 2020

Accepted Manuscript published online 31 July 2020
This work is licensed under a Creative Commons Attribution-NonCommercial 4.0 International License. ded from Bioscientifica.com at 04/26/2023 09:42:29AM 